\section{Analysis of the characteristics of chinese traditional sports culture in the new period}

\author{
SC Wang* \\ Faculty of Sports Science, Ningbo University, China
}

\section{Abstract}

Through cultural consciousness, the characteristics of traditional Chinese sports culture in the new period are analyzed and studied, and the traditional Chinese sports culture in the new period has the following six characteristics: 1 . Sports social model of "etiquette" 2 . Sports personality model of the gentleman's way; 3 . The sports behavior mode of the golden mean; 4 . The social nature of sports of socialism with Chinese characteristics; 5 . Sports cultural nature of emotional culture; 6 limited competitive sports competition.

\section{More Information}

*Address for Correspondence: SC Wang, Faculty of Sports Science, Ningbo University, China, Tel: +865748818 0000;

Email: andywutong@foxmail.com

Submitted: 10 July 2019

Approved: 19 July 2019

Published: 23 July 2019

How to cite this article: Wang SC. Analysis of the characteristics of chinese traditional sports culture in the new period. J Sports Med Ther. 2019; 4: 053-060.

https://doi.org.10.29328/journal.jsmt.1001044

Copyright: @ 2019 Wang SC. This is an open access article distributed under the Creative Commons Attribution License, which permits unrestricted use, distribution, and reproduction in any medium, provided the original work is properly cited

Keywords: New era; Traditional chinese sports culture; Features

Check for updates

\section{Introduction}

The Chinese traditional sports culture is an organic part of Chinese traditional culture, the cultural characteristics of is the basic sign it differs from other cultures accurately, the characteristic of a culture is truly understand a culture inherent in advance can accurately grasp the characteristics of the Chinese traditional sports culture and carry forward the inheritance and development of Chinese traditional sports culture premise In the present Chinese sports academic study of the characteristics of the Chinese traditional sports culture under the condition of little and not enough comprehensive, through to the Chinese traditional sports culture consciousness, so as to explain the characteristics of the Chinese traditional sports culture has the important significance of academic research. Therefore, in the new era, the characteristic of Chinese traditional sports could help to inherit culture.

\section{Chinese traditional sports culture consciousness}

Chinese traditional sports culture is the Chinese nation in the process of its development, based on their physiological and psychological needs of social development and it created a variety of physical culture and the western sports culture have very big difference, it is produced to meet the development needs of the Chinese nation, therefore, in the new era of Chinese traditional sports culture in addition to having some of the properties of western sports culture, also has the western sports culture is not sports culture has the qualities of the Chinese nation traditional culture characteristic, at the same time also has the social development stage of the Chinese nation in the new period of cultural traits.

Chinese traditional sports culture is one of an organic part of Chinese traditional culture, it originated in the need of national survival and life, it is since it was born, the imprint of the Chinese traditional culture, carrying the genetic inheritance of the traditional culture of the Chinese nation, has become the style of a cultural heritage of the Chinese nation traditional culture as a child of the traditional culture of the Chinese nation culture of Chinese national traditional sports culture, it also contains the basic characteristics of its parent culture and era characteristics, and in the social mode of Chinese traditional sports culture Personality model and behavior model, and on this basis, take traditional national sports as cultural characteristics, derived other characteristics.

\section{Analysis of chinese traditional sports culture charac- teristics}

\section{The sports social model of "the way of etiquette"}

Simply put, the model of sports society is a certain pattern of the operating mechanism to adjust the relationship between various elements in the structure of sports society. In order to achieve effective regulation, it must have a certain standard, which is the basic situation of the sports society and the mainstream cultural values of the society. Therefore, the adjustment standard of China's national traditional sports social structure is the basic national conditions of China and the mainstream values of Chinese culture in a certain period. 
That is to say, the mainstream social and cultural values and cultural spirit of a certain period in China are put into this kind of cultural ceremony of "etiquette" to adjust the relationship between various elements in the traditional sports social structure of the Chinese nation.

This "way of etiquette" carries the mainstream social and cultural values and cultural spirit of China in a certain period. the way to adjust the sports social model of China's national traditional sports culture is the most basic of China's national traditional sports culture.

The traditional sports culture of the Chinese nation originates from the national sports culture which contains the local conditions and customs of each nation. Each nationality's local conditions and customs, the folk custom is the etiquette way concrete manifestation. Although, our national traditional sports activities, most do not have the same as western sports with strict rules of the game activities and sound organization. However, our national traditional sports can also be carried out in an orderly way and passed down from generation to generation. It relies on the etiquette of our nation's traditional sports culture. With the way of etiquette, China's national traditional sports culture can not only be passed down from generation to generation, but also its cultural values and cultural spirit can be extended from generation to generation. This in our country it can be verified in some national sports handed down from the memory of ancestors and national heroes. For example, in the first half of the first lunar month, there is a climbing performance on the slope meeting held by the miao people in guangxi. Climbing pole is to commemorate the miao national hero meng ziyou and passed down the sports activities. Or, "bai, All the people who have made contributions to the bai nationality are regarded as their patron gods and worshipped by them. In order to worship these gods, the bai people hold traditional sports activities every year, such as "walking around the mountains and forests", "Lantern Festival", "torch festival" and "butterfly festival". In addition, every year and festival, the branch of the laku tribe, the kucong people, are all in need.

There are many kinds of traditional national sports in China, which cannot be cited as examples. However, by sorting out some representative traditional national sports in China, we can see that the way of etiquette is one of its important basic characteristics. Some other characteristics of Chinese traditional sports culture are also included. For example, Sun xingxiang and wang shaochun, in "on the emotional characteristics of Chinese traditional culture" [1], have made cultural interpretations on such events as ritual archery, martial arts, wood archery and dragon boat racing.

\section{"Shooting ceremony" -- competitive shooting, more competitive}

"Shooting ceremony" -- shooting competition, more ceremony. 1In primitive societies the ancients learned to shoot with arrows while hunting. Shooting is the meaning of archery, which originated from human labor and production practices, and later developed into a traditional sport of the Chinese nation. There are many different archery activities in the traditional sports of the Chinese nation. Such as bow shot, a catapult shot, catapult, riding shot, shot li, li shot and so on. Archery was also the six arts of the education system of the aristocracy of the zhou dynasty: ritual, music, archery, royal culture and literature.

The ritual shooting was the archery system in the western zhou dynasty. It has a set of strict, cumbersome archery etiquette and grade regulations. The aim is not to shoot, but to examine the moral behavior of the archer through the process of shooting. it aims to select useful talents meeting the moral standards of the ruling class. The rites of archery were the rites of archery in the zhou dynasty. And according to the big shot, target shot, yan shot, rural shot is divided into four grades. Archers correspond to sons of heaven, princes, doctors and doctors respectively, and should never confuse grades.

During the spring and autumn period and the warring states period, Confucius praised zhou li highly and proposed the "self-sacrifice and self-sacrifice", which further strengthened the etiquette in archery. In archery, a traditional national sports activity, the Confucian ethics and values are directly endowed with a whole set of Confucian etiquette thoughts. Moreover, archery is regarded as an educational means to cultivate social elites, thus making the society more elite. Therefore, the shooting ceremony is not so much to compete skills in archery, but to compare character through the process of archery. The sports social pattern of "the way of etiquette" contained in this sport activity is one of the characteristics of Chinese traditional sports culture. And this characteristic is also the traditional culture of other nations in the world do not have.

\section{Martial arts - the art of internal and external cultivation}

There are nearly a thousand kinds of traditional sports in China. Although there are a large number of traditional sports, most of them belong to a specific ethnic group. Only a few sports, such as martial arts, are traditional Chinese sports that are Shared by all 56 ethnic groups in China. Therefore, it is also the Chinese nation traditional sports most representative item.

To be exact, wushu is a noun that appeared only in modern times. There is no such thing as wushu in ancient China. It is from the ancient Chinese martial arts, martial arts or called wuyi evolved. Professor ruan jizheng said: "the so-called Chinese traditional martial arts culture is nothing but the behavior pattern and activity pattern formed by the traditional Chinese people in dealing with physical conflicts."[2].

Although wushu is also physical exercise as a means of physical activities, but in the whole process of its learning 
and practice, attaches great importance to the cultivation of martial ethics, the so-called "martial first xiude". As the ancients said, "to judge the heart of the text, the view of virtue". Martial arts was originally a "barbaric movement" of dancing with the ruler, fighting with each other for life, and depending on the strength of the martial arts. However, when it was endowed with martial virtues by the traditional Chinese culture, it changed from "good fighting" to "comity first" and became a noble and educated "civilized movement". In order to cultivate wushu virtues, Chinese traditional culture endows wushu with the connotation of etiquette, making it the epitome of Chinese traditional culture.

In history, there was a close relationship between wu and li. Confucius, the founder of Confucianism, advocated "rites" in the spring and autumn period, and the "archery" and "royal" in the "six arts" of the zhou dynasty were originally directly related to ancient martial arts. In the ceremony of Chinese martial arts, there are strict worship ceremony, ancestor worship ceremony, comparison ceremony, performance ceremony, meeting ceremony and so on. In Chinese martial arts, the "three cardinal principles and five permanent principles" are also very important. Such as pay attention to "up and down", "respect for teachers", "one day as a teacher, a lifetime as the father", the most taboo "bully the ancestor", between teachers and brothers "long and young orderly, up and down". In terms of code of conduct, he emphasizes "harmony is the most precious", "courtesy comes first", "comity comes first", "the soft can overcome the strong", "moral persuasion", "internal sanctity and external king", "justice", "internal and external cultivation" and so on.

Wushu, the "way of etiquette", is similar to western boxing and free combat.

\section{Wood shot- the tool of moral education}

Wood shot, is a very popular Chinese tang dynasty similar to the son of the western ground ball of a kind of indoor ball games live- movement, also known as "the fifteen-pin ball game 5". Because it's a flat piece of land with 15 wooden poles at one end during the game, the player stands at the other end of the field and throws the wooden ball out of his hand to hit the target on the wooden post.

It is a kind of typical Chinese traditional cultural ethics and moral activities with sports as the carrier. Because it is the game equipment directly as a tool of enlightenment. The whole process of the game is a complete moral and ethical education process. Before the game, 10 of the 15 posts will be made into red posts, and the other 5 will be made into black posts. And write "benevolence, righteousness, propriety, wisdom, faith, warmth, kindness, courtesy, frugality and comity" on the red wooden column, representing the noble virtue; and will be "proud, slow, stingy, greedy, excessive ", respectively written on the five black wooden column, said the low moral. When the game, to hit the red column for the winner, and a certain reward. The one who hits the black pillar is the loser and should be punished accordingly. So wood shoot is also a kind of ancient Chinese allegorical education.

\section{Dragon boat race - we are in the same boat}

Dragon boat race is also called dragon boat race, dragon boat race, is also a representative of the traditional Chinese sports items More than 30 of China's 56 ethnic groups have the custom of racing dragon boats on the Dragon Boat Festival.

Dragon boat is made up of dragon and boat. The dragon is the totem of the Chinese nation, the Chinese nation also identify themselves as the descendants of the dragon. Therefore, the dragon for the Chinese nation is a very special significance. It can be said that the Chinese nation's traditional culture is the dragon culture, the dragon is also the symbol of the Chinese nation. When the dragon and the boat together become the dragon boat has become the traditional sports of the Chinese nation, it is destined to be the carrier of Chinese traditional culture and carry forward the spirit of national culture.

The dragon boat culture has a long history. About the origin of dragon boat RACES around the world Opinions vary [3]. For commemorating the patriotic poet qu yuan and sacrifice qu yuan, also for praying for good weather and the dragon god said, etc. Although, due to the differences in the geographical environment and social development, dragon boat RACES are taking place all over the country. Different customs, dragon boat culture also shows a variety of activities, but its cultural load.

Dragon boat RACES are held every year on the Dragon Boat Festival and have become an iconic custom around the festival activities. Before the dragon boat race, all over the general have dragon, the grand ceremony of sacrifice god, but the content is different. For example, in fujian, Taiwan is to go to mazu temple worship; Qu yuan to the river to the lake, tears luo city, before the race must first qu temple dynasty brain, will be the dragon head for - worship the dragon head, and then install the dragon head on the boat for racing, not only worship the dragon god, but also commemorate the original E; In guangdong, before the Dragon Boat Festival will be out of the water from the Dragon Boat Festival, in the temple in the south China sea after the south China sea god, installed on the dragon head, dragon tail, and then ready to race. And buy a pair of paper small rooster placed on the dragon boat, think can bless the ship safe. In sichuan, guizhou and other individual areas, in the river kill chat first class.

Dragon boat RACES use dragon boats of different sizes. Such as guangzhou huangpu, suburban area dragon boat is longer, 38 meters; Miluo county in hunan province dragon boat is 16-22 meters long; the dragon boat is 18 meters long in fuzhou, fujian province. Similarly, the number of copepods varies from place to place. There are 24-48 people scratching their hands on the dragon boat in hunan. Thirty-two people scratched their hands on a dragon boat in fuzhou, fujian province. In appearance, dragon boats are also different from 
ordinary boats. Dragon boat is generally long and narrow, narrow, boat headdress dragon head, the stern of the dragon tail. The color of bibcock has red, black, ash to wait for color, all resemble with the head of dragon lamp, attitude is differ. Generally carved into wood, to be painted (also paper, yarn). Dragon tail multi-purpose wood carving, carved scales. Besides dragon head and tail, dragon boat also has decoration such as gong and drum, flag or hull painting. Dragon boats are decorated differently from place to place.

Dragon boat race in the process, the dragon boat oar, drummer, helmsman to drum rhythm, unity and cooperation, heart to a place to make, strength to a place with, can drive the dragon boat speed. The competition was grand and spectacular. The dragon boats flying in the water, the fluttering flags, the flying trumpets and the splashing spray are integrated into the thousands of cheering spectators on the riverside. Where are the dragon boat RACES, where are the exciting people.

Remnants of the spray, fluttering dragon flags, flying dragon boat, flying horn, and the cross-strait dare to shout caper crowd integration. Where there are dragon boat RACES, there are exciting crowds. Oarsman, drummer, helmsman is a collective battle. One boat, two boats, several boats, multiple boats, participants, said the square dragon boat race. Every dragon boat race is hundreds or thousands of people, many tens of people participate, performers or spectators, all of them are crazy, happy. The dragon boat race is a popular cultural form that is popular and actively participated in by the people. Dragon boat culture star patriotism culture. The dragon is the symbol of the strength of the Chinese nation. The dragon boat culture contains the humanistic spirit of "loving the motherland and the people, being optimistic and moving forward", which is like a long and unceasing historical river, nourishing the land of jianghan and moulding the spiritual character and moral outlook of the sons and daughters of jingchu. Dragon boat race, memorial qu yuan, xiangyan become common. Qu yuan is the model of the spirit of the Chinese people's flag. Qu yuan's patriotic feelings, concerned about the people, noble personality, in different times, different societies, and even different countries, have a strong appeal. Through the year after year dragon boat race Dragon Boat Festival activities customs, the inheritance of the dragon culture of the Chinese nation, carry forward the Chinese nation patriotism, optimism, self-improvement, enterprising cultural spirit. It is of great significance to enhance the sense of national identity, which is the centripetal force and cohesion of a high nationality.

\section{The "gentleman's way" model of sports personality}

The main function of culture is that it has a mechanism for adjusting to society. Society is made up of people, so shaping personality has become one of the important purposes of culture. Personality is the thought, character and behavior endowed by certain social culture. That is to say, different cultures will create different personalities. Personality is divided into individual and collective. Different cultures give different ideas, personalities and behaviors to social members. Therefore, there must be some differences between Chinese traditional sports culture and other sports cultures. In this sense, the personality of a culture is one of its basic characteristics. China's national traditional sports culture is a part of China's traditional culture, they shape the personality must be the same, that is, "junzi". Therefore, in the sports personality model, the establishment of the "gentleman's way", is also one of the basic characteristics of China's traditional sports culture. A gentleman is obviously different from the gentlemen, knights and warriors pursued by other nations.

What is a gentleman? The gentleman is the result of Confucian's choice, explanation and promotion of various Chinese personality models. Confucian personality design into the gentleman, the gentleman has become a traditional Chinese text the embodiment of the ideal personality. In the course of the development of Chinese society, the social elites of different times keep on growing. Through the interpretation of Confucian classics, the new era elements are introduced into the gentleman, which enriches and develops the connotation of the gentleman, and makes it always conform to the development of The Times, and makes it become the ideal personality of the past, present and future of Chinese culture.

Yu qiuyu believed that the Chinese ideal of personality is condensed into a gentleman is "the Confucian will to the future generations - do a gentleman, do not do villain, have handed down? It's handed down. Moreover, it was well known. As long as the Chinese, even if illiteracy, also happy to be called a gentleman, and never want to be seen as villain. It is a cultural miracle that it has been so popular for thousands of years and has been deeply rooted in the hearts of people. Mr. Yu qiuyu summarized the way of a gentleman in his book the way of a gentleman into nine aspects, namely: 1 . The virtue of a gentleman; 2 . The virtue of a gentleman; 3.4 , the gentleman week and no more than the gentleman, 5 , the gentleman is open, 6 , the middle of the gentleman,7, the gentleman is polite, 8 , the gentleman is not a tool, 9 , the gentleman knows shame [4]. It also explains.

Having understood the general meaning of a gentleman, let's have a look at the gentleman shaped in the traditional Chinese sports culture.

Chinese traditional national sports, wushu is its main representative. In traditional martial arts competitions, there are established rules and customs, both than wuyi, more than wude. A person without morality, even if the martial arts, but the loss of morality, rude, will not be recognized as a winner, because he lost the hearts of the people, and people's minds of the gentleman Discrepancy. Only a gentleman with high martial arts skills and good martial ethics can be recognized as 
a hero and a winner. The martial arts master who is extolled by people must also be a person of high prestige. Therefore, in the inheritance of traditional martial arts, there is a set of rules of propriety and righteousness, such as receiving disciples, passing on skills, and the relationship between masters and apprentices. And the way of propriety and righteousness of each school.

For another example, in China's traditional national sports activities, although there are no strict rules, each participant or group will consciously accept the corresponding "etiquette and righteousness" constraints, to win the youdao, not opportunistic. Opportunistic even if you win, also do not win the arms, like a villain. This is unacceptable and shameful to most participants. Moreover, the competition victory or defeat standard, also often takes the spot to be the standard. In the process of Chinese traditional board games, there is even a saying of "observing chess without saying what a gentleman really is". All these represent the powerful enculturation function of Chinese traditional sports culture. National traditional sports is an important carrier of national culture inheritance, development and communication. Therefore, by carrying out the national traditional sports activities extensively, it is helpful for the ethnic people to grow into the social members recognized by the ethnic group.

\section{“The golden mean" mode of sports behavior}

The doctrine of the mean is an important philosophical thought of Confucius. The theoretical basis of the doctrine of the mean is unity of man and nature. The unity of heaven and man is an important proposition in the history of Chinese philosophy, which is also the most basic way of thinking of Chinese people. There are different explanations for the unity of man and nature. One of them is that there are mainly three viewpoints of Taoism, Confucianism and Buddhism. Generally speaking, Chinese culture pays attention to the harmony between man and nature, the relationship between man and society, and the harmony between man and man.

Under the influence of Confucianism, Taoism and Buddhism, through the complementarity of the three, the Chinese nation has formed its own way of thinking, mainly including dialectical thinking, intuitive thinking and neutralizing thinking. The way of thinking of neutralization originates from the understanding of "holding the middle", "holding the middle" and "tolerating". Starting from the Confucian thought of "the doctrine of the mean", it absorbs the concept of "the middle way" of the school of Buddhism and the dialectic of "the middle line" of the unity of opposites of Taoism.

The neutralization way of thinking from the doctrine of the mean is a holistic way of thinking. That is to say, thinking about problems and looking at things always starts from the whole. For example, the concept of health maintenance in traditional Chinese sports regards people's spirit, spirit and spirit as a whole to practice, and forms the methodology of both internal and external practices of traditional martial arts. Exactly so, some people think Chinese traditional sports is a kind of "round culture",. It attaches great importance to the "hold", "hold", namely "in holding dual-purpose", pay attention to balance, "knock at both ends", opposed to doing things too much, not the pursuit of diode, advocate everything must be just right, because "too far", it emphasizes the mutual tolerance and harmony between things, "all things and education without harm, parallel and not contrary", through the complementary and win-win situation, the most "and but different", the ideal state of "unity".

Therefore, "the doctrine of the mean" has become the philosophy of Chinese people and established the doctrine of the mean in terms of behavior mode tao has become one of the basic characteristics of Chinese culture and its sub-culture as well as one of the basic characteristics of China's traditional sports culture.

The guiding, breathing, qigong and other activities in Chinese traditional sports culture as well as the theoretical basis of TCM exercise and health preservation are all based on the theory of the unity of heaven and man, Yin and Yang, five elements, meridians and viscera. Starting from these basic theories, it has formed the unique integral view of life of Chinese traditional sports and traditional Chinese medicine, namely the unity of spirit and shape. From this, the essential view of life in accordance with the heaven way based on the spirit and spirit is derived God and other life maintenance! Methods and methods.

Improving and promoting people's physical and mental health is the common goal of traditional health keeping sports and modern sports in China, but their emphases are different. The emphasis of modern sports, especially western competitive sports, is to keep fit, to improve the physiological functions of various systems of the human body, and to strengthen the physical appearance, etc., so as to achieve the purpose of strengthening the physique. Competitive sports is often through a short period of intense exercise, so that the body is fully exercised, the pursuit of the ultimate effect of sports. But our country traditional keeping in good health sports request the dynamic and static union, the form and spirit raises together. It does not pursue short-term strenuous exercise, but pays more attention to the adjustment of self-spirit, that is, the adjustment of the heart, through the person's essence, breath, god of the exercise, requires posture, breathing, and the idea of the overall exercise, the pursuit of the state of neutralization, so as to achieve.

In terms of the mechanism of fitness, western sports make people breathe more deeply, consume more oxygen and increase heart rate through exercise fast, high blood pressure, promote human metabolism; The human body can also be developed according to its requirements through specific parts of the body for exercise or specialized training. It is also effective in improving people's mental health. 
China's traditional health sports generally require exercisers to relax their body and mind, abandon distracting thoughts, and carry out coordinated exercises with breathing in a state of tranquility. This kind of movement can make airframe consumes oxygen quantity to reduce, heartbeat is sincere slow, blood pressure drops, improve body quality on the whole. This is very different from modern western sports.

The doctrine of the mean developed on the philosophical basis of the unity of man and nature is the mainstream traditional way of thinking of the Chinese nation in the past, present and future. Chinese sports culture is bound to carry the mainstream way of thinking of the Chinese nation -- the doctrine of the mean, and form the concept of the doctrine of the mean sports culture.

The concept of the mean sports culture has been playing an important role in the formation and development of Chinese sports culture. Moderate sports cultural viewpoint that the Chinese nation in the face of foreign sports culture under the condition of "invasion" aggressively, with neither, self-pity, also don't boast and decoration, neither wholesale westernization, nor negate the doctrine of the mean attitude and selectively absorb the best part of the western sports culture, with the Chinese national traditional sports culture integration in, and, constitute the contemporary Chinese sports culture, promote the integration of Chinese and foreign sports culture.

In addition, the doctrine of the mean also makes our traditional sports culture pay less attention to competition and more attention to harmony and artistic performance. Therefore, in China's traditional sports, the forms of direct physical contact and confrontation are much less than the western sports. Even martial arts, which has a very military function, also pays attention to the point in the traditional games. The doctrine of the mean also enables participants in China's traditional sports activities to behave in a moderate and not extreme way. We seldom hear or see violent conflicts between participants in China's traditional sports activities. Violent clashes are common in western sports. Therefore, the concept of the mean of sports culture has become the characteristics of China's traditional sports culture different from other sports cultures.

\section{The social nature of sports under socialism with Chinese characteristics}

China is a socialist country, and the nature of the country determines that China's modern national traditional sports culture must be a socialist sports culture. This is our country sports culture, is also our country national traditional sports culture is distinguished from the western capitalist sports culture one of the important signs. This is China's national traditional sports development to the time and space to which it belongs to the characteristics of the Times.
Therefore, China's national traditional sports must undertake to meet the needs of all ethnic sports and to meet the national needs of traditional sports. Specifically speaking, in terms of meeting the needs of all ethnic groups for sports, traditional sports of all ethnic groups are not only a kind of sports activity, but also a kind of custom activity of all ethnic groups, carrying the rich national cultural connotation of all ethnic groups. The existence of national traditional sports is the need of inheriting national custom and culture, and it is also an indispensable part of national custom and culture activities. Social members of an ethnic group can not only meet their physiological needs for physical activities, but also their psychological needs for national identity and sense of belonging through sports activities in custom activities, so as to strengthen communication among social members and promote the improvement of national cohesion. In the meet Demand for traditional sports, nations, countries need to by advocates to develop the ethnic traditional sports activity, maintain ethnic characteristics of various nationalities, organizing national traditional sports events, the traditional minority national sports meeting, to promote the cultural exchange between nationalities, inheritance of Chinese traditional sports culture, enhance the mutual understanding between different ethnic groups and fusion, strengthen ethnic identity, belonging to the state, carry forward the spirit of patriotism, to promote the unity of various nationalities, safeguard national unity and prosperity of the development of cultural pluralism and diversity of all ethnic groups of landscape. At the same time, through the development of traditional ethnic sports activities, to promote and improve the physical health of the people of all ethnic groups, and enrich the amateur cultural life of the people of all ethnic groups. Finally, we will serve the $\mathrm{tt}^{*}$ cause of China people I.

\section{The nature of emotional culture and sports culture}

China is an emotional cultural society with the pursuit of meeting psychological needs as the first demand. Emotional culture is based on the development of morality and art to meet people's emotional needs. Therefore, in ancient China, there was no highly developed scientific culture to meet the cultural needs of material nature. Instead, there was a highly developed humanistic spirit with the main content of Confucianism, Taoism and Buddhism, and the cultural characteristics of which were rule of virtue, ethics, patriarchal clan, ethics, harmony, sensibility and social connections to meet the first need of the Chinese nation

Tao yuanming's "idyllic life" in harmony with nature has become an ideal poetic lifestyle for Chinese people. In the society of emotional culture, people are generally conscious of the rule of ethics and morality, and are not accustomed to the strict and institutionalized legal constraints. In the folk formed the "law does not fold the masses", "love is greater than the law", "the people do not fight with the official" traditional psychology, it is generally believed that "the crime 
of the prince and the common people the same crime" is just a saying. From the perspective of the overall needs of people and classes, Chinese ethnic groups mainly pursue emotional satisfaction. Logically speaking, psychological needs come first, then material needs, and finally spiritual needs. This is also the reason why China has not become a country dominated by religion, but has formed a universal recognition of Confucianism, Taoism and Buddhism. So. In this social and cultural environment, the traditional Chinese national sports culture is naturally branded with the brand of emotional culture, which inevitably has the basic characteristics of emotional culture.

These characteristics are more prominent in mass sports and school sports. For example, in all kinds of school sports competitions, there will be awards such as sports spiritual civilization award, sports morality award and so on. MAO zedong also put forward the instruction of "friendship first, competition second" to Chinese sports. In traditional Chinese sports, mentoring relationships are held together by emotions, with a day as a teacher and a lifetime as a father. This is completely different from the contractual relationship between coaches and athletes in western sports. Although China's modern sports culture has been formed through the mutual integration of Chinese and foreign sports cultures, and the title of mentoring has been replaced by coaches and athletes, although the relationship between them is different from the traditional mentoring relationship in the past, it is not completely the same as the relationship between coaches and athletes in the west. Because there is a teacherstudent relationship between our coaches and athletes, that is, the relationship between elders and juniors, rather than a contractual relationship. The athletes with the same coach still use the names of "big brother", "second brother" and "little sister" in private, which is still very common and shows a strong brand of emotional culture.

Most western societies belong to the material culture, which takes the material demand as the first demand, the spiritual demand as the second, and the psychological demand as the third. Therefore, in order to meet such needs, the concepts of science, religion, competition, conquest and war have become the basic characteristics of western material culture. Similarly, the western sports culture, which is produced in the social environment of physical culture, inevitably has the basic characteristics of physical culture. The spirit of "faster, higher and stronger" of Olympic culture is the concrete representation of this physical sports culture. Therefore, it is difficult for them to understand the emotional connotation of Chinese wushu. Because in their thoughts

\section{Limited competitive sports competition}

Sport is a body culture created by human beings. In the process of development, the body culture in the west has been endowed with the cultural characteristics of competition.
Competition is the nature of living things. However, it is only the law of the jungle in the world of natural biology, which is not completely suitable for the development of human society. However, the west applies this theory to the development of human society, and the emergence of western competitive sports is its best portrayal.

Under the guidance of the "faster, higher, stronger" Olympic culture and the guidance of the individualism of western culture, competitive sports in the western competitive sports have been performed incisively and vividly. Training that pushes the limits of human physiology at the expense of individual health; At the expense of human ethics, abuse. doping, bribery of officials and referees, influence of law enforcement, etc., in order to win the competition in the competition. And these ACTS in the symbol of human spiritual civilization in the Olympic Games are also common. These unscrupulous competitions for victory have greatly impacted human ethics and morals and destroyed the pursuit of beauty and beauty.

Only competition within the framework of basic human ethics and morals is benign competition, and can truly meet the various physical and psychological needs of human beings for sports, that is to say, competitive sports must abide by limited competition in order to create happiness and beauty for mankind, to adapt to the development of human culture, and to truly benefit mankind. In China, excessive competition, in which unscrupulous ACTS against human ethics such as sacrificing one's health in exchange for winning the competition, is prohibited and is not advocated. Therefore, sports, the unique human body culture, emerged on the Chinese soil, under the influence of the traditional Chinese culture "the unity of man and nature", stresses the harmony between man and nature, between man and society, and has not developed into a competitive sports culture like western sports. Even in the development of western sports in China, there is limited competition. For example, before the reform and opening up, China's sports were carried out under the guidance of chairman Mao's thought of "friendship first, competition second". At that time, although we also stressed the competitiveness of the game, but more emphasis on sports to enhance the friendship between the two sides. After the reform and opening up, we keep pace with The Times, emphasize the competition of the competition, also pay more attention to the competition, but pay more attention to the competition within the framework of basic human ethics that is to advocate limited competition. We are opposed to the use of stimulants in sports, sports means that harm human health, and sports behaviors that violate human ethics such as match-fixing and black whistle. Similarly is the sports competition, our country each kind of competition also has the card prize with the western sports, in recent years our country has cancelled the medal list in the national games, weakened the people in the sports competition day by day the strong gold medal consciousness. At the same time, there are 
spiritual civilization award and sportsmanship award with Chinese socialist characteristics in all kinds of competitions in China, which is an impossible phenomenon in western sports competitions. Therefore, limited competition is also one of the characteristics of Chinese modern sports culture.

\section{Conclusion}

In order to characteristics of traditional Chinese national sports culture overview of the following fifth points 1 . Sports social model of "etiquette"; 2 . The sports personality model of "gentleman's way"; 3 . The sports behavior mode of "the golden mean"; 4. The social nature of sports under socialism with Chinese characteristics; 5 . The nature of sports culture; Limited competitive sports competition.

\section{References}

1. Xiang SX, Shaochun W. On the emotional characteristics of Chinese traditional culture, zhejiang sports science. 2014; 36: 1-51.

2. Jizheng $\mathrm{R}$, Weiwen $\mathrm{A}$. A draft of Chinese traditional martial arts culture [M]. Guangzhou publishing house, January 2015

3. People's Daily overseas edition. 2011.

4. Qiuyu Y. ay to begentleman. [M]. Beijing. Beijing united press. 2014; 8. 